\title{
Empathy Diminishes Prejudice: Active Perspective-Taking, Regardless of Target and Mortality Salience, Decreases Implicit Racial Bias
}

\section{Travis J. Pashak*, McCall A. Conley, Drew J. Whitney, Samuel R. Oswald, Stephanie G. Heckroth, Evan M. Schumacher}

Saginaw Valley State University, University Center, MI, USA

Email: `tjpashak@svsu.edu, maconley@svsu.edu, djwhitne@svsu.edu, sroswald@svsu.edu, sgheckro@svsu.edu, emschum1@svsu.edu

How to cite this paper: Pashak, T. J., Conley, M. A., Whitney, D. J., Oswald, S. R., Heckroth, S. G., \& Schumacher, E. M. (2018). Empathy Diminishes Prejudice: Active Perspective-Taking, Regardless of Target and Mortality Salience, Decreases Implicit Racial Bias. Psychology, 9, 13401356.

https://doi.org/10.4236/psych.2018.96082

Received: April 27, 2018

Accepted: June 25, 2018

Published: June 29, 2018

Copyright $\odot 2018$ by authors and Scientific Research Publishing Inc. This work is licensed under the Creative Commons Attribution International License (CC BY 4.0).

http://creativecommons.org/licenses/by/4.0/

\section{(c) (i) Open Access}

\begin{abstract}
Racism, and particularly the oppression of Black citizens, remains a significant problem in the United States. This manuscript reports on an experiment studying the effects of mortality salience and active perspective-taking empathy on racial bias. Specifically, social empathy was hypothesized to counteract the increased in-group preferential bias typical of those primed with mortality salience. The sample consisted of $n=111$ White emerging adults affiliated with a small Midwest American university. Death anxiety and active perspective-taking were experimentally manipulated, and the dependent variables were implicit bias change scores (pre-test versus post-test on the Race-Related Implicit Association Test using White/Black faces) and explicit racial prejudice (self-report scores on the Quick Discrimination Inventory and Scale ot Ethnocultural Empathy). The four experimental groups did not differ on implicit bias change scores or explicit discrimination scores-neither main effects nor interaction effects were statistically significant. However, the QDI and SEE were correlated $(r=.76, p>.001)$, thus supporting their construct validity, and the pre-scores on the Race IAT across the whole sample were statistically significantly higher than the post-scores, with a moderate effect size $(t(110)=3.13, p=.002$, eta-squared $=.08)$. Findings appear to indicate that engaging in active perspective-taking, regardless of the race of the target and regardless of the presence of mortality salience, leads to decreased implicit racial prejudice. Empathy training in various clinical and educational settings could lead to a reduction in prejudiced attitudes, and ultimately aid in the dismantling of American racism.
\end{abstract}




\section{Keywords}

Racism, Terror Management Theory, Empathy, Emerging Adulthood, Implicit-Bias

\section{Introduction}

"Every single smile, and every single tear, reminders of the moments we shared in the instant we were here. If everyone will die, and everyone will lose, then who you gonna love in the meantime before it catches you?" (Pierre, 2012)

Racism remains a poignant societal problem in the United States and elsewhere. Occurring in various manifestations ranging from overt hostility to covert or even unconscious prejudice, racism is embedded in practically every facet of American life. Specifically, White Americans as the majority demographic stand to benefit from a host of factors which, in obvious or less visible ways, grant superior access to goods, services, opportunities, licenses, experiences, and freedoms - this all at the direct of expense of other groups.

\subsection{Consequences of Racism}

People of color, and Black Americans in particular, appear to suffer from myriad disadvantages tied to the nation's history of slavery and legacy of racism. Just to highlight a few representative issues: as compared to White Americans, Black Americans report less satisfaction with their communities, families, finances, and lives in general (Pew Research Center, 2017); Blacks have the highest rates of poverty compared to other racial/ethnic groups, and also are the only group to see median household income stagnation over the past two decades rather than growth (United States Census Bureau, 2017); and the majority of Black Americans (71\%) have experienced discrimination, with nearly one quarter of Blacks specifically reporting experiencing unfair work practices regarding hiring, pay, or promotion (Pew Research Center, 2017). Further, experiences of racial discrimination/prejudice against Black people are linked to important negative consequences, including increased stress response, increased rates of physical illness, increased health risk behaviors (e.g., smoking, drinking, overeating, unsafe sex practices), and overall decreases in mental health manifesting as anxious, posttraumatic, depressive, and somatic symptoms among others (Pascoe \& Richman, 2009; Pieterse, Todd, Neville, \& Carter, 2012). Given this concerning (albeit not novel) state of affairs, racism's psychological underpinnings, maintenance mechanisms, and possible points of intervention are of interest.

\subsection{Terror Management Theory}

One intriguing model for the conception and perpetuation of racial prejudice involves death anxiety. According to terror management theory (e.g., Greenberg, Pyszczynski, \& Solomon, 1986), prejudicial beliefs (i.e., artificial feelings of superiority as compared to certain other groups, as well as negative affect/cognition/behavior 
toward those other groups) may arise from, and be exacerbated by, the realization of one's own eventual and inevitable death and dying. As self-aware beings capable of foreseeing their own demise (consciously or at least unconsciously), humans experience somewhat crippling anxiety concerning their eventual non-existence, and thus work fervently toward denial. To combat this death anxiety, research shows that people engage in a variety of defense mechanisms-both to practically stave off death as long as possible (i.e., literal immediate defenses) and to ensure that some aspect of the self lives on indefinitely (i.e., long-term metaphorical defenses). These reactions to mortality, termed proximal and distal defenses, respectively (Pyszczynski, Greenberg, \& Solomon, 1999), occur in a predictable sequence when prompted. Proximal defenses occur first in response to conscious reminders of death (and may include actions/thoughts related to immediate pragmatic self-preservation, such as wearing a seatbelt or helmet, exercising, or choosing healthy foods). Following a brief delay while death salience is pushed into the subconscious by the proximal defenses, the distal defenses take over to further protect against death anxiety (by unconsciously bolstering one's self-esteem as defined by cultural worldviews and connecting to symbolic sources of permanence, such as one's nation, religion, career, or race). In essence, the second step in the dual-process death defense model is to strengthen, unconsciously, one's beliefs in their causa sui project (Becker, 1973), a means of extending relevance beyond one's lived timeline and into infinitude.

Thus, terror management theory informs dialogue about racism in that racial prejudice (aligning with and preferring one's own racial/ethnic group, boosting cultural worldview adherence, distancing from any out-groups, and having less trust/care/value assigned to others) could be one particular form of distal defense mechanism. In other words, people attempt to achieve symbolic permanence by living on through their same-race peers and progeny. And in fact, the findings bear this out. For instance, Bradley and colleagues (2012) found that individuals primed with mortality salience scored higher on a test of implicit racial bias than the non-primed control group. In a similar vein, Schimel and colleagues (1999) found that subjects primed with mortality salience responded to questionnaires with more stereotyped views of Blacks.

Considering this line of research, we hypothesized that a method of mitigating racism (particularly in the context of mortality salience) would be to coach people on stretching their "in-group" to include other races/ethnicities. If people could be influenced to feel a connection with diverse others, perhaps through some sort of engaged learning experience and compassion for said individuals, then the aforementioned inflation of bias toward others may be in fact be prevented or reduced.

\subsection{Improving Social Empathy}

Stretching one's in-group to include the novel experiences of others is to essentially promote the diversification of social networks, and ultimately, to cultivate empathy. According to Barker (2003, p. 141), empathy is "the act of perceiving, 
understanding, experiencing, and responding to the emotional ideas of another person." This is supported by Rogers' (1980) definition of the state of empathy, which he argues is to accurately understand and perceive the internal frame of reference and emotional components and meanings of another, as if they were one's own, while maintaining one's own identity. Rogers elaborates, stating that empathy is to feel another's pleasure or hurt as if it were one's own while keeping oneself separate-importantly, entering another's private perceptual space and experiencing with them. Social empathy, then, is simply applying those principles of empathy to an entire social group rather than to individuals. Specifically, Segal (2011, p. 266) defines social empathy as "the ability to understand people by perceiving or experiencing their life situations and as a result gain insight into structural inequalities and disparities." Segal also posits that increased empathy on the societal level is the key to effecting a positive change in social injustice. The importance of increasing empathy in a social context is to facilitate a decrease in disparity between groups.

If social empathy on the broad scale can theoretically address injustice by changing individuals' beliefs and perspectives, then one would expect small-scale social empathy training and interventions to provide empirically observable benefits. A growing base of literature supports this notion. For instance, a study by Spanierman, Neville, Liao, Hammer, and Wang (2008) found that formal on-campus diversity training events were indeed related to changes in college students' racial beliefs; similarly, Neville, Poteat, Lewis, and Spanierman (2014) longitudinally followed White students and found that diversity experiences such as interracial friendships during college did indeed alter racial ideology. Further, studies by Soble, Spanierman, and Liao (2011) and Gutierrez and colleagues (2014) showed that effective social empathy training can be achieved not solely through in-person encounters, but also through other mediums-such as exposure to documentaries on White privilege and systemic racism, and even role-playing video games involving avatars experiencing racial discrimination. Thus, the literature appears to show that social empathy can be observably trained or strengthened through planned intervention, with measurable positive consequences including diminished racial colorblindness and diminished prejudicial/stereotyped views. If terror management theory offers a plausible explanatory model for the origins and maintenance of racism (i.e., mortality salience boosts preferential treatment of racial in-group members), and empathy training offers a possible method of counteracting this effect (i.e., social empathy stretches the in-group to "people" rather than "White people" for instance, and thus decreases racial prejudice), then the remaining consideration is to identify an appropriate population within which to test this model.

\subsection{Emerging Adulthood}

Coined by Arnett and Taber (1994), the term emerging adulthood refers to the phase/process of human development positioned between late adolescence and young adulthood. Researchers have recently estimated the age range of emerging 
adulthood to be approximately 18 to 29 (Arnett, Kloep, Hendry, \& Tanner, 2011), and have noted that this period of development is marked by drastic psychological upheaval and dynamic changes to identity. Emerging adults experience significant adjustments in views concerning morality, ethnic identity, and religiosity/spirituality; they see major transformations in their demographic status and mental health; and undergo noteworthy developments in cognitive reasoning and theory of mind, just to name a few topics (Arnett \& Tanner, 2006). Thus, emerging adults are relevant to the current project because they are poised to benefit from social empathy training, stretch their cognitive structures of "in-group," and yield potentially long-lasting decreases in their implicit and explicit biases toward diverse others.

Further, emerging adults affiliated with college/university settings (which is an enormous portion of the nation, given that over half of American high school graduates are initiating college studies) were identified as the population of interest. They were chosen as the focus because places of higher education frequently offer didactic sessions on topics such as racial empathy, cultural sensitivity, and diversity inclusion (e.g., in coursework, in employee in-service training, and in lectures given by invited campus speakers). Thus, the college/university environment is ripe with opportunities to introduce its constituents to new or challenging ideas about actively engaging in the perspectives of others-and emerging adults are undergoing the necessary cognitive/affective developments to gain from such interventions. Hence, this study was designed to take advantage of the unique positioning of university-context emerging adults in exploring terror management theory and social empathy.

\subsection{Theory Integration and Hypotheses}

The theoretical grounding for this project includes the literatures on terror management theory (a model of the role of death anxiety and human denial of mortality; Greenberg, Pyszczynski, \& Solomon, 1986), social empathy (a model of cross-group empathy and compassion geared toward the reduction of social injustices; Segal, 2011), and emerging adulthood (a developmental theory regarding the uniquely dynamic experiences of those approximately ages 18-29; Arnett \& Tanner, 2006), as a backdrop for the endeavor to dissect and decrease racism in the United States. Specifically, this experimental study proposes that social empathy training may counteract the prejudice-heightening effects of mortality salience, by essentially expanding the in-group to include those who may have previously been perceived as being part of an out-group (i.e., other races). Thus, we hypothesized that there will be group differences on implicit and explicit racial bias between those primed and not primed with death anxiety, and between those trained and not trained with social empathy.

\section{Methods}

\subsection{Sample}

1) Target size. We used the program $G^{\star}$ Power to estimate necessary sample 
size for the study (Faul, Erdfelder, Lang, \& Buchner, 2007). We started by considering the research questions, the first of which involved comparing implicit change scores (pre-test vs. post-test on racial bias) of four groups (mortality salience vs. control; empathy training vs. control). By using the average effect size of $r=.35$ found in Burke, Martens, and Faucher's meta-analysis on mortality salience experiments (2010), and the design of a $2 \times 2$ factorial ANOVA, with a set to .05 and power set to $.80, \mathrm{G}^{*}$ Power suggested an estimated sample size of 67 participants. Next, we ran $G^{\star}$ Power estimates for the MANOVA necessary to address the second research question regarding explicit survey outcomes (overt racial prejudice on multiple self-report instruments between the four groups), and found similar sample size requirements. To allow room for minor procedural errors, attrition, and have a sample size easily divisible into the four experimental groups, we decided to pursue a minimum usable sample size of $n=100$.

2) Participants collected. The sample consisted of emerging adults ages 18 to 30 at a small/mid-sized public university in the Midwest United States. Emerging adults provided a suitable sample due to their potential for mental plasticity concerning views of morality and ethnic identity (i.e., expansion of their perceived in-group). Particularly, emerging adults affiliated with a university are continually exposed to various perspective challenging experiences increasing the ability for in-group malleability or social empathy to occur within the developmental group. A total of $n=151$ individuals were brought into the lab and initiated administration of the study procedures. Within those, 7 cases were unusable due to attrition or item response problems (4.6\%), another 7 cases were removed from analyses due to problematic data cleaning regarding the implicit bias scores (4.6\%), and finally, 26 more cases were removed from analyses $(17.2 \%)$ in order to narrow the sample down to solely White participants due to the uneven distribution of racial minority participants between experimental groups-and further because the notions of implicit and explicit bias in the study primarily dealt with White people's in-group preferential bias and out-group prejudice against Black people. Thus, the final sample size was $n=$ 111.

The participants had a mean age of $M=19.30$ years $(S D=2.18)$, and were primarily female ( $n=86,77.5 \%)$. The sample included emerging adult members of the campus community across levels of study and employment, including freshmen ( $n=73,65.8 \%)$, sophomores $(n=12,10.8 \%)$, juniors $(n=12,10.8 \%)$, seniors $(n=10,9.0 \%)$, fifth-years and beyond $(n=1, .9 \%)$, and staff/administrators/employees $(n=3,2.7 \%)$. They all identified racially/ethnically as White $(n=$ $111,100 \%)$, and the majority identified religiously as Christian $(n=83,74.8 \%)$ with other faiths/worldviews represented to a lesser extent (Judaism $(n=3$, 2.7\%), Agnosticism/Atheism ( $n=6,5.4 \%)$, and "None" $(n=19,17.1 \%)$ ). The modal responses regarding socio-economic status indicators were that parents' highest level of education was "Some College" ( $n=28,25.2 \%)$, family income was "Less Than $\$ 40,000$ " ( $n=25,22.5 \%)$, and self-assigned perception of SES 
was "Middle Class" ( $n=44,39.6 \%)$. These three indicators, each on 7-point Likert-style scales, were combined to produce an estimated SES scale which had a Cronbach's alpha of $\alpha=.72$, a range from 1.67 to 6.67 (potential range of 1 to 7), and an average score of $M=3.84(S D=1.19)$. Overall, the sample was primarily female and Christian, but represented a broad array of educational levels, socio-economic statuses, and ages within the emerging adulthood period.

\subsection{Procedure}

We marketed the opportunity to participate in the study via physical fliers posted around campus, as well as electronic fliers posted to a social media webpage for members of the campus community. Further, participation was incentivized by the option to enter in a drawing for one of six $\$ 50$ gift cards, as well as (some but not all) participants having the option to earn partial course credit.

After signing up online and being assigned a timeslot, participants arrived for the study and were escorted to computer stations prepared for administration of the study. Once informed consent was established, subjects were set up on the computers and administered the following, in order: demographics form; pre-intervention round of the test for implicit racial bias; priming essay condition (either an essay about death inducing mortality salience or a neutral essay about a dental visit); video condition and empathy response prompts (either a documentary about racism or a neutral video about career growth); gap task (word search puzzle); post-intervention round of the test for implicit racial bias; and two self-report surveys of explicit bias/discrimination. We assessed bias using both explicit and implicit instruments because prior literature (e.g., Brauer, Wasel, \& Niedenthal, 2000) has shown these constructs to be independent. Both administrations of the implicit testing were completed using E-Prime software, the video conditions were presented on a large projector screen in the room, and all the remaining forms and essays were completed online through the Survey Gizmo platform. Survey Gizmo randomized which essay condition subjects encountered (i.e., blind to the experimenters), while the video condition was controlled by the experimenters (i.e., administered to the whole lab room of participants at once, and alternated throughout the weeks of data collection to keep group numbers balanced as they grew). Upon completion of all the data collection activities, participants were presented with a brief educational form with exit information regarding the purposes of the study, contact information for the principal investigator and IRB, links to a local counseling service, and an external link to enter in the drawing for the gift card incentive.

\subsection{Measures}

1) Demographics. A brief demographics form was administered through Survey Gizmo which collected data on core aspects participant identity (e.g., age, race/ethnicity, gender, religion, affiliation to the university, etc.).

2) Race IAT. The Race-Related Implicit Association Test (Race IAT; Green- 
wald, McGhee, Schwartz, 1998) is one specific form of the IAT, a computerized assessment instrument designed to measure the strength of automatic connection between two concepts, as operationalized by differences in response time on categorization tasks. On most IATs, the association being measured is between a simple perceived valence/preference/bias of some kind (e.g., pleasant vs. unpleasant; good vs. bad; positive vs. negative; safe vs. dangerous) and some human identity characteristic (e.g., White vs. Black race; male vs. female sex; liberal vs. conservative politics; Christian vs. Muslim religion). By using two separate keys on a keyboard, respondents are trained to categorize, as quickly as possible, new stimuli appearing on the computer screen into one of two options. After a brief training period with one variable at a time, the two concepts are administered in a mix-for instance, an IAT assessing preference for young versus old faces may ask the participant to categorize both positive/negative words and images of young/old faces into left/right keys as they appear intermittently in one trial. Thus, some trials provide a set of compatible pairings (i.e., the combination goes along with a known stereotype or plausible bias) while others provide a set of incompatible pairings (i.e., the combination goes against the known stereotype). The key notion based on cognitive science is that users' latencies (i.e., response times to categorizing a stimuli), on average, tend to be faster for the compatible trials in individuals who hold the targeted association, because the cognitive load required to categorize linked concepts onto the same side is lighter. Thus, when controlling for individuals' average speed, the average latency discrepancies between compatible and incompatible trials (i.e., the effect size of the difference) are deemed to be evidence that the implied association exists to a certain degree. This allows researchers to measure constructs which may be too sensitive, embarrassing, or socially undesirable to be reliably assessed with face-valid instruments (Greenwald et al., 1998).

The Race IAT specifically measures the strength of an association between positive/negative words and the faces of two different races-in essence, the strength of one's implied racial bias or racism (Greenwald et al., 1998). We used a version of the Race IAT which presented pleasant/unpleasant words and images of Black/White faces, designed closely after the "Project Implicit" Race IAT provided by Harvard University at https://implicit.harvard.edu/implicit/takeatest.html (Project Implicit, 2011), which was found reliable in a study by Sabin, Nosek, Greenwald, and Rivara (2009). This particular version is seven trials, and randomizes whether the participant first completes the compatible or incompatible trials. Further, in order to ensure quality data, we utilized numerous suggestions from Greenwald, Nosek, and Banaji (2003) on improving the coding and data cleaning of latencies. Namely, we followed a version of their "improved algorithm" which included the following: using data from blocks $3,4,6$, and 7, rather than only blocks 4 and 7; eliminating trials with latencies over $10,000 \mathrm{~ms}$, rather than having a less systematic screening method; using data from all trials, rather than eliminating the first two 
trials of each block; deleting trials with latencies under $400 \mathrm{~ms}$, rather than recoding to the boundary; using latencies to correct responses, rather than adding a latency-penalty for incorrect responses; and not doing any mathematical transformations, rather than log-transforming as previously suggested.

3) MAPS. The Mortality Attitudes Personality Survey (MAPS; Rosenblatt, Greenberg, Solomon, Pyszczynski, \& Lyon, 1989) is an essay prompt used widely in terror management research to induce mortality salience. Participants are prompted to spend approximately five minutes reflecting and writing about their expected experiences of death and dying, and to evaluate their thoughts, emotions, and experiences throughout the event. The alternative to the MAPS (used in the control condition) is a similarly-worded essay prompt in which subjects are asked to envision a routine dental visit.

4) Empathy Induction Task. The fourth step in the study procedure was to display a video, upon which subjects would next reflect and engage in focused empathy skills concerning a particular individual featured in the video. According to prior empathy literature (e.g., Gutierrez et al., 2014), there is an important difference between "active perspective-taking" and "passive perspective-taking" forms of empathy, such that active forms produce greater change in attitude and behavior toward groups or individuals which are oppressed, marginalized, or minority status. Gutierrez and colleagues define active perspective-taking as the "projected identity" achieved when one "not only imagines how another person feels in a given situation, but also directs how that person responds" (Gutierrez et al., 2014: p. 372). They go on to specify that one strong method of inducing such empathy is avatar play, or role-playing video-games designed to walk an individual through the lived experiences of the oppressed, such as racist remarks or discriminatory treatment from others. Due to concerns about time constraints, we opted not to utilize a video-game intervention, but instead sought evidence in the literature of active perspective-taking through briefer writing tasks. Batson, Chang, Orr, and Rowland (2002) found that by playing an audio recording of an interview prefaced with instructions for participants to imagine the emotional impact upon one of the characters, that similar levels of active empathy and stronger altruistic outcomes could be achieved. Their script read as follows: "While you are listening to this interview, try to imagine how Jared feels about what has happened and how it has affected his life. Try to feel the full impact of what Jared has been through and how he feels as a result." Thus, we used a similar prompt before starting the video in both conditions.

In the social empathy experimental condition, participants viewed a 20 minute clip of a documentary titled True Colors available on YouTube (Pearce \& Ross, 1991; https://www.youtube.com/watch?v=oi_DF9Iu2xA). The clip documented, using hidden cameras, the different experiences that two men (one White and one Black) encountered as a result of their race across different situations, demonstrating the various acts of racism and racial attitudes that occur and exist within everyday contexts. When implemented by Soble and colleagues (2011), the clip was found to have the effect of increasing subject scores of racial 
awareness, White empathy, and White guilt as compared to the control condition.

In the control empathy condition, participants were exposed to a neutral video stimulus which did not involve any references to racism. The clip was a TED Talk available on YouTube titled "How to Find and do Work You Love" (TEDx Talks, 2012; https://www.youtube.com/watch?v=jpe-LKn-4gM) and was approximately 18 minutes in duration, focusing on the life experiences of a White adult male and pursuing one's passion in life. In watching the True Colors video, participants were asked to actively adopt Glenn's perspective (the Black male who faced numerous racist setbacks to establishing himself in a new city) whereas participants in the control condition were asked to empathize with Scott at the TED Talk (the White male speaker who shared his views about career development pathways).

In order to make the empathy task a truly active adoption of perspective with the target individual, another essay task followed the video. This involved giving subjects five minutes to write freely about the three prompts below, phrased vaguely enough that they could plausibly be relevant to real life experiences of either Glenn or Scott. Importantly, participants were reminded to respond as though they really were Glenn/Scott (i.e., they were told "How do you [the person in the video] perceive this situation, and what do you do?"):

a) You are in class and the professor asks a question, to which you raise your hand and provide an answer. The professor then gives a somewhat condescending response: "wow, that was surprisingly articulate."

b) You are pulled over while driving home. The police officer explains that you have a tail light out, and immediately begins writing you a ticket. You explain that you were unaware, and that you'll get it fixed right away, but he refuses to let you go with a warning-insisting that you deserve the ticket.

c) You forgot your phone and you ask another student at the library if you can quickly borrow theirs to text your roommate-the student says their phone battery ran out. You instead resort to trying to send your roommate a Facebook message from the library computer, when you hear the other student's phone start to ring.

5) Gap Task Word Search. In order to give a delay long enough for mortality salience to recede into subconscious awareness (Greenberg, Arndt, Simon, Pyszczynski, \& Solomon, 2000), and to ensure that empathy salience could do the same (if perchance, it exists), a 5-minute gap task was employed which involved subjects engaging in an online word-search task to ensure they were distracted from conscious thoughts of death and/or empathy. The words in the puzzle all dealt with a neutral topic-school/office supplies.

6) SEE. The Scale of Ethnocultural Empathy (SEE; Wang, Davidson, Yakushko, Savoy, Tan, \& Bleier, 2003) is a measure of empathy toward people of racial and ethnic backgrounds who are different from the test taker's own background. The SEE is a 31-item Likert-type scale ranging from 1 (strongly disagree) to 6 
(strongly agree), with total scores across a possible range of 31 to 186 . Higher scores indicate more empathy toward cultures different from the test-taker's own.

7) QDI. The Quick Discrimination Index (QDI; Ponterotto, Burkard, Rieger, Grieger, D'Onofrio et al., 1995) measures prejudicial attitudes toward racial diversity and attitudes about women's equity. The QDI is a 30-item Likert-type scale ranging from 1 (strongly disagree) to 5 (strongly agree), with total scores across a possible range of 30 to 150 . Lower scores indicate more prejudicial and racist responses.

\section{Results}

A two-way ANOVA was conducted to explore the impacts of mortality salience and social empathy induction upon implicit bias change scores, as measured by the Race IAT score differences between pre-test and post-test. Data were divided into two groups based on which essay condition participants completed (dental essay for control group, death essay for mortality salience group) and divided into two groups based on which empathy condition participants completed ( TED Talk video for neutral empathy group, True Colors video for social empathy group). The interaction effect between essay condition and empathy condition was not statistically significant, $F(1,107)=2.90, p=.091$. The main effect for essay condition was not statistically significant, $F(1,107)=.09, p=.764$; nor was the main effect for empathy condition, $F(1,107)=.72, p=.398$. Thus, the four experimental groups did not statistically significantly differ in their Race IAT change scores. See Table 1 for a summary of the scores.

A two-way MANOVA was conducted to explore the impacts of mortality salience and social empathy induction upon explicit discrimination/prejudice scores, as measured by the SEE and the QDI. Data were divided into the same experimental groups noted above. The interaction effect between essay condition and empathy condition was not statistically significant, $F(2,106)=.15, p=.863$, Wilks' Lambda $=.99$. The main effect for essay condition was not statistically

Table 1. Implicit and explicit bias scores by experimental group.

\begin{tabular}{|c|c|c|c|c|}
\hline Group & $\begin{array}{l}\text { Pre-Test Race IAT } \\
\qquad M(S D)\end{array}$ & $\begin{array}{l}\text { Post-Test Race IAT } \\
\qquad M(S D)\end{array}$ & SEE $M(S D)$ & QDI $M(S D)$ \\
\hline $\begin{array}{c}\text { Control Essay/Control } \\
\text { Video }\end{array}$ & $.55(.39)$ & $.30(.38)$ & $\begin{array}{l}135.96 \\
(26.52)\end{array}$ & $\begin{array}{l}107.32 \\
(20.51)\end{array}$ \\
\hline $\begin{array}{c}\text { Control Essay/Social } \\
\text { Empathy }\end{array}$ & $.34(.42)$ & $.31(.34)$ & $\begin{array}{l}134.45 \\
(19.43)\end{array}$ & $\begin{array}{l}107.93 \\
(16.52)\end{array}$ \\
\hline $\begin{array}{c}\text { Mortality Salience/Control } \\
\text { Video }\end{array}$ & $.51(.39)$ & $.43(.39)$ & $\begin{array}{l}134.89 \\
(14.93)\end{array}$ & $\begin{array}{l}107.89 \\
(12.66)\end{array}$ \\
\hline $\begin{array}{c}\text { Mortality Salience/Social } \\
\text { Empathy }\end{array}$ & $.58(.36)$ & $.43(.40)$ & $\begin{array}{l}133.68 \\
(19.70)\end{array}$ & $\begin{array}{l}106.38 \\
(17.28)\end{array}$ \\
\hline Full Sample & $.50(.40)$ & $.37(.38)$ & $\begin{array}{l}134.72 \\
(20.27)\end{array}$ & $\begin{array}{l}107.37 \\
(16.75)\end{array}$ \\
\hline
\end{tabular}


significant, $F(2,106)=.03, p=.972$, Wilks' Lambda $=.99$; nor was the main effect for empathy condition, $F(2,106)=.08, p=.925$, Wilks' Lambda $=.99$. Thus, the four experimental groups did not statistically significantly differ on their SEE or QDI scores. See Table 1 for a summary of the scores.

A paired-samples $t$-test was conducted to evaluate the possibility that, regardless of experimental group (i.e., across the whole sample), the empathy induction task may have impacted implicit racial bias. Indeed, there was a statistically significant decrease in implicit bias scores on the Race IAT from pre-test $(M=.50$, $S D=.40)$ to post-test $(M=.37, S D=.38), t(110)=3.13, p=.002$ (two-tailed). The mean decrease in implicit bias scores was .13 with a $95 \%$ confidence interval ranging from .04 to .21 , and the eta-squared statistic of .08 indicated a moderate effect size. Case-wise, the majority of participants $(n=64,57.7 \%)$ had lower implicit bias scores at post-test than at pre-test. See Figure 1 for a boxplot of the mean comparison.

Of note, the SEE and QDI total scores were statistically significantly correlated with one another $(r=.76, p>.001)$, but neither were statistically significantly correlated with either the Race IAT pre-test scores or the Race IAT change scores. This is worth mentioning, as it presumably supports the construct validity of the SEE and QDI, as well as enforces the notion that implicit and explicit forms of bias may function somewhat separately (e.g., Brauer et al., 2000).

\section{Discussion}

The hypothesis regarding the main effect of mortality salience upon bias (i.e., that those primed with death anxiety would subconsciously bolster their self-esteem, and manifest this through increased racial in-group preference) as well as the hypothesis regarding the main effect of social empathy/active

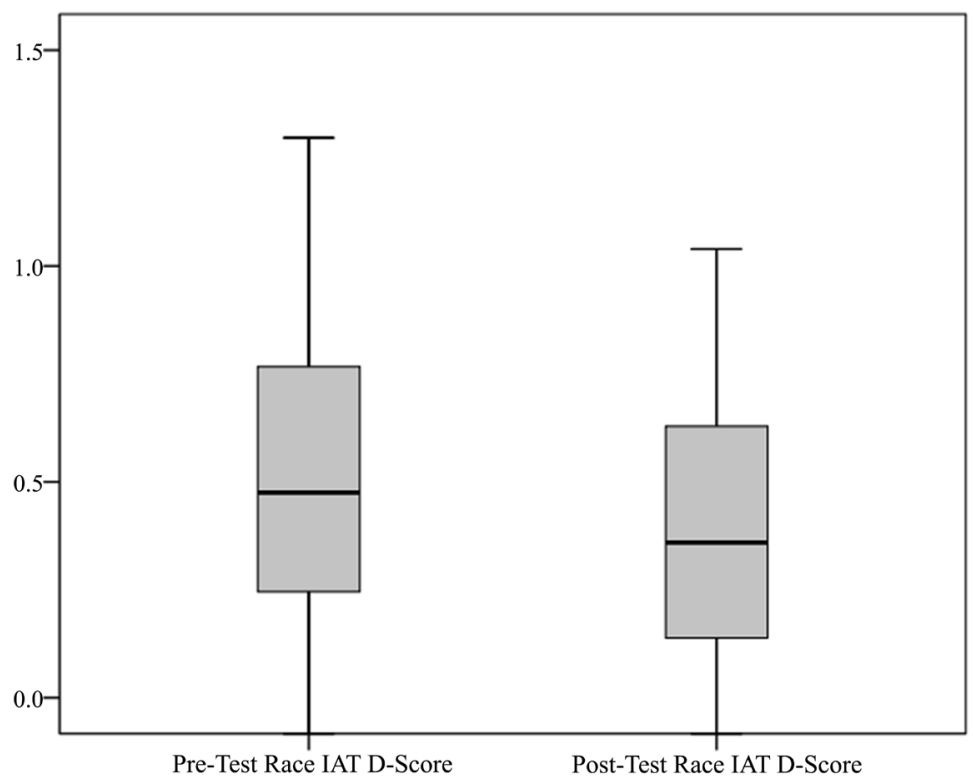

Figure 1. Boxplot comparing pre-test and post-test means on the Race IAT. 
perspective-taking upon bias (i.e., that White students trained to empathize with a Black man's experiences of racism would subconsciously stretch their in-group, and manifest this through decreased racial in-group preference) were not supported by the data comparing experimental groups. However, we made an interesting discovery that the whole sample overall, regardless of experimental group, exhibited a decrease in implicit bias against Blacks from pre-test to post-test. Despite the relatively small sample size and the well-established robustness of the IAT in prior literature (Joy-Gaba \& Nosek, 2010), we found that this change in scores was statistically significant and of moderate effect size.

Our proposed interpretation of the findings is that activating empathy toward a stranger-of any sort, not exclusively a racial out-group individual-may lead to decreased implicit bias against others. Perhaps the cognitive network involved in imagining another's lived experiences, attempting to share their feelings and perceptions, and actively taking their perspective in some decision/reaction/behavior, is enough to slightly change the way people view members of other groups-toward a less prejudicial stance. This would account for why, despite not specifically empathizing with a Black person, the White participants in the TED Talk condition exhibited decreased bias. Further, we argue that enacting empathy-again, toward any stranger-has a subsequent self-esteem-bolstering effect; this would account for why, despite having a need for a distal defense against mortality salience, the participants in the death essay condition nevertheless exhibited decreased bias as well.

Worth immediate consideration, a likely counter-argument to our interpretation (that the mechanism of enacting empathy for a novel individual caused decreased out-group implicit bias) is that instead of a real change occurring, there was a short-term practice effect in participants' approach to the Race IAT. There is, however, a clear rebuttal to this concern, built into the way the Race IAT calculates its d-scores: the difference between stereotype-compatible response latencies (i.e., speed of pairing Black faces with negative words) and stereotypeincompatible response latencies (i.e., speed of paring Black faces with positive words) is divided by the pooled standard deviation of all response latencies for each individual participant. Thus, if a typical participant responds more rapidly on the post-test than the pre-test, due to having gained practice with the Race IAT, this does not account for a change in d-scores because the changed rate of response overall would be washed out in the formula.

Another likely counter-argument to our interpretation of the findings is that the Race IAT may not truly measure what it intends (i.e., unconscious bias against Blacks), but rather, some other construct such as familiarity with Black people or early socialization/exposure to negative stereotypes about Blacks; as these and other concerns about the IAT's interpretation have been raised recently (Gawronski, 2009). While some critiques of the IAT are indeed warranted (e.g., it may not be completely immune to faking/malingering; it may not assess truly unconscious content but rather content which one typically intends to 
hide; it may be tapping into cultural awareness of certain biases rather than one individual's adoption of said bias), none of these issues adequately leads to an alternative explanation for our findings. In other words, if Race IAT scores are primarily explained by one's early life socialization (i.e., rather than one's personal level of bias), then a short-term empathy activity should not logically provoke any change-but it did, even in the experimental conditions which did not discuss race whatsoever.

\section{Limitations}

Certainly, the study has some limitations. Key concerns include the narrowed focus upon White emerging adults in university settings (a group generally overrepresented in psychology research); null findings regarding the core hypotheses of differences between the four experimental groups' change scores; and the fact that our data contradict previous literature regarding mortality salience causing increased bias against out-groups (e.g., Bradley et al., 2012). Further, the claims made in our interpretation of the findings leave further research to be desired. To test these interpretations more directly, we give a few suggestions for follow-up research: for instance, future studies using a similar model would likely benefit from including a non-empathizing control condition. Whereas our current design framed the same-race empathy activity as a "control" condition (i.e., White participants empathizing with hypothetical experiences of Scott, the White speaker in the TED Talk video), this inadvertently allowed generalized empathy to remain a possible mechanism of change within each of the four experimental groups. To address this, a fifth group could be administered a video irrelevant to race or human relations (e.g., documentary on birds) and asked to complete a perspective-taking task which would not enact empathy (e.g., "imagine yourself bird-watching...”). Other conditions to help specify the mechanism could include empathizing with a stranger vs. empathizing with a friend or relative; learning about the other individual through a video, text vignette, or meeting them in-person; or framing the empathy-inducing scenarios to be either more or less explicitly dealing with race (e.g., the prompt regarding a peer refusing to lend their cell phone could be rewritten such that the peer specifically mentions aloud their distrust for one's racial group).

\section{Conclusion}

This article reports on an experimental study involving death anxiety, social empathy, and implicit racial bias. While the four experimental groups did not differ on key outcome variables (scores on the SEE and QDI, and change scores on the Race IAT), there was evidence of an overall decrease in implicit racial bias across the sample as a whole, which appears attributable to the active perspective-taking task. Specifically, the results point toward the mental process of empathy-for any stranger-acting as a mechanism which decreases the degree to which one holds unconscious prejudice. This interpretation warrants further research to clarify and dissect the exact causal sequence of change, but offers some 
inspiration for possible real-world applications. Namely, that training emerging adults on university campuses to empathize and actively adopt the perspectives of others' lived experiences (even within same-race individuals), can be an effective stepping-stone toward decreased racism, improved interracial relations, and growth of acceptance, inclusivity, and multicultural-competence.

\section{References}

Arnett, J. J. \& Tanner, J. L. (Eds.). (2006). Emerging Adults in America: Coming of Age in the $21^{\text {st }}$ Century. Washington DC: American Psychological Association. https://doi.org/10.1093/acprof:oso/9780195309379.001.0001

Arnett, J. J., \& Taber, S. (1994). Adolescence Terminable and Interminable: When Does Adolescence End? Journal of Youth and Adolescence, 23, 517-537. https://doi.org/10.1007/BF01537734

Arnett, J. J., Kloep, M., Hendry, L. B., \& Tanner, J. L. (2011). Debating Emerging Adulthood: Stage or Process? Oxford, NY: Oxford University Press. https://doi.org/10.1093/acprof:oso/9780199757176.001.0001

Barker, R. L. (Ed.). (2003). The Social Work Dictionary (5th ed.). Washington, DC: NASW Press.

Batson, C., Chang, J., Orr, R., \& Rowland, J. (2002). Empathy, Attitudes, and Action: Can Feeling for a Member of a Stigmatized Group Motivate One to Help the Group. Personality and Social Psychology, 28, 1656-1666. https://doi.org/10.1177/014616702237647

Becker, E. (1973). The Denial of Death. New York, NY: The Free Press.

Bradley, K., Kennison, S., Burke, A., \& Chaney, J. (2012). The Effect of Mortality Salience on Implicit Bias. Death Studies, 36, 819-831. https://doi.org/10.1080/07481187.2011.605987

Brauer, M., Wasel, W., \& Niedenthal, P. (2000). Implicit and Explicit Components of Prejudice. Review of General Psychology, 4, 79-101.

https://doi.org/10.1037/1089-2680.4.1.79

Burke, B. L., Martens, A., \& Faucher, E. H. (2010). Two Decades of Terror Management Theory: A Meta-Analysis of Mortality Salience Research. Personality and Social Psychology Review, 14, 155-195. https://doi.org/10.1177/1088868309352321

Faul, F., Erdfelder, E., Lang, A.-G., \& Buchner, A. (2007). G*Power 3: A Flexible Statistical Power Analysis Program for the Social, Behavioral, and Biomedical Sciences. Behavior Research Methods, 39, 175-191. https://doi.org/10.3758/BF03193146

Gawronski, B. (2009). Ten Frequently Asked Questions about Implicit Measures and Their Frequently Supposed, But Not Entirely Correct Answers. Canadian Psychology, 50, 141-150. https://doi.org/10.1037/a0013848

Greenberg, J., Arndt, J., Simon, L., Pyszczynski, T., \& Solomon, S. (2000). Proximal and Distal Defenses in Response to Reminders of One's Mortality: Evidence of a Temporal Sequence. Personality and Social Psychology Bulletin, 26, 91-99. https://doi.org/10.1177/0146167200261009

Greenberg, J., Pyszczynski, T., \& Solomon. (1986). The Causes and Consequences of a Need for Self-Esteem: A Terror Management Theory. In R. F. Baumeister (Ed.), Public Self and Private Self (pp. 189-212). New York, NY: Springer.

Greenwald, A. G., McGhee, D. E., \& Schwartz, J. L. (1998). Measuring Individual Differences in Implicit Cognition: The Implicit Association Test. Journal of Personality and Social Psychology, 74, 1464-1480. https://doi.org/10.1037/0022-3514.74.6.1464 
Greenwald, A. G., Nosek, B. A., \& Banaji, M. R. (2003). Understanding and Using the Implicit Association Test: An Improved Scoring Algorithm. Journal of Personality and Social Psychology, 85, 197-216. https://doi.org/10.1037/0022-3514.85.2.197

Gutierrez, B., Kaaz, A., Chu, S., Ramirez, D., Samson-Samuel, C., \& Carnes, M. (2014). "Fair Play": A Videogame Designed to Address Implicit Race Bias through Active Perspective-Taking. Games for Health Journal: Research, Development, and Clinical Applications, 3, 371-378. https://doi.org/10.1089/g4h.2013.0071

Joy-Gaba, J., \& Nosek, B. (2010). The Surprisingly Limited Malleability of Implicit Racial Evaluations. Social Psychology, 41, 137-146. https://doi.org/10.1027/1864-9335/a000020

Neville, H. A., Poteat, V. P., Lewis, J. A., \& Spanierman, L. B. (2014). Changes in White College Students' Color-Blind Racial Ideology over 4 Years: Do Diversity Experiences Make a Difference? Journal of Counseling Psychology, 61, 179-190. https://doi.org/10.1037/a0035168

Pascoe, E. A., \& Richman, L. S. (2009). Perceived Discrimination and Health: A Meta-Analytic Review. Psychological Bulletin, 135, 531-554. https://doi.org/10.1037/a0016059

Pearce, K., \& Ross, S. (1991). Primetime Live [Television Broadcast]. New York, NY: ABC News. http://www.youtube.com/watch?v=oi_DF9Iu2xA

Pew Research Center (2017). 2016 Racial Attitudes in America Survey. Washington DC. http://www.pewsocialtrends.org/dataset/2016-racial-attitudes-in-america-survey/

Pierre, J. C. (2012). Everyone Will Die [Recorded by Motion City Soundtrack]. On Go [CD]. Los Angeles, CA: Epitaph Records.

Pieterse, A. L., Todd, N. R., Neville, H. A., \& Carter, R. T. (2012). Perceived Racism and Mental Health among Black American Adults: A Meta-Analytic Review. Journal of Counseling Psychology, 59, 1-9. https://doi.org/10.1037/a0026208

Ponterotto, J., Burkard, A., Rieger, B., Grieger, I., D’Onofrio, A., Dubuisson, A., Heenehan, M., Millstein, B., Parisi, M., Rath, J., \& Sax, G. (1995). Development and Initial Validation of the Quick Discrimination Index (QDI). Educational and Psychological Measurement, 55, 1016-1031. https://doi.org/10.1177/0013164495055006011

Project Implicit (2011). Take a Test. https://implicit.harvard.edu/implicit/takeatest.html

Pyszczynski, T., Greenberg, J., \& Solomon, S. (1999). A Dual-Process Model of Defense against Conscious and Unconscious Death-Related Thoughts: An Extension of Terror Management Theory. Psychological Review, 106, 835-845. https://doi.org/10.1037/0033-295X.106.4.835

Rogers, C. R. (1980). A Way of Being. Boston, MA: Houghton Mifflin Company.

Rosenblatt, A., Greenberg, J., Solomon, S., Pyszczynski, T., \& Lyon, D. (1989). Evidence for Terror Management Theory: I. The Effects of Mortality Salience on Reactions to Those who Violate or Uphold Cultural Values. Journal of Personality and Social Psychology, 57, 681-690. https://doi.org/10.1037/0022-3514.57.4.681

Sabin, J., Nosek, B., Greenwald, A., \& Rivara, F. (2009). Physicians' Implicit and Explicit Attitudes about Race by MD Race, Ethnicity, and Gender. Journal of Health Care for the Poor and Underserved, 20, 896-913. https://doi.org/10.1353/hpu.0.0185

Schimel, J., Simon, L., Greenberg, J., Solomon, S., Pyszczynski, T., Waxmonsky, J., \& Arndt, J. (1999). Stereotypes and Terror Management: Evidence that Mortality Salience Enhances Stereotypic Thinking and Preferences. Journal of Personality and Social Psychology, 77, 905-926. https://doi.org/10.1037/0022-3514.77.5.905 
Segal, E. A. (2011). Social Empathy: A Model Built on Empathy, Contextual Understanding, and Social Responsibility that Promotes Social Justice. Journal of Social Service Research, 37, 266-277. https://doi.org/10.1080/01488376.2011.564040

Soble, J. R., Spanierman, L. B., \& Liao, H. (2011). Effects of a Brief Video Intervention on White University Students' Racial Attitudes. Journal of Counseling Psychology, 58, 151-157. https://doi.org/10.1037/a0021158

Spanierman, L. B., Neville, H. A., Liao, H. Y., Hammer, J. H., \& Wang, Y. F. (2008). Participation in Formal and Informal Campus Diversity Experiences: Effects on Students' Racial Democratic Beliefs. Journal of Diversity in Higher Education, 1, 108-125. https://doi.org/10.1037/1938-8926.1.2.108

TEDx Talks (2012). How to Find and Do Work You Love: Scott Dinsmore. https://www.youtube.com/watch?v=jpe-LKn-4gM

United States Census Bureau (2017). Income and Poverty in the United States: 2016. Washington DC.

https://www.census.gov/content/dam/Census/library/publications/2017/demo/P60-259 .pdf

Wang, Y., Davidson, M., Yakushko, O., Savoy, H., Tan, J., \& Bleier, J. (2003). The Scale of Ethnocultural Empathy: Development, Validation, and Reliability. Journal of Counseling Psychology, 50, 221-234. https://doi.org/10.1037/0022-0167.50.2.221 